\title{
Non-adherence to drug therapy and drug acquisition costs in a national population - a patient-based register study
}

Bo Hovstadius ${ }^{1,2^{*}}$ and Göran Petersson ${ }^{1,3}$

\begin{abstract}
Background: Patients' non-adherence to drug therapy is a major problem for society as it is associated with reduced health outcomes. Generally, approximately only 50\% of patients with chronic disease in developed countries adhere to prescribed therapy, and the most common non-adherence refers to chronic under-use, i.e. patients use less medication than prescribed or prematurely stop the therapy. Patients' non-adherence leads to high additional costs for society in terms of poor health. Non-adherence is also related to the unnecessary sale of drugs. The aim of the present study was to estimate the drug acquisition cost related to non-adherence to drug therapy in a national population.

Methods: We constructed a model of the drug acquisition cost related to non-adherence to drug therapy based on patient register data of dispensed out-patient prescriptions in the entire Swedish population during a 12-month period. In the model, the total drug acquisition cost was successively adjusted for the assumed different rates of primary nonadherence (prescriptions not being filled by the patient), and secondary non-adherence (medication not being taken as prescribed) according to the patient's age, therapies, and the number of dispensed drugs per patient.

Results: With an assumption of a general primary non-adherence rate of 3\%, and a general secondary nonadherence rate of 50\%, for all types of drugs, the acquisition cost related to non-adherence totalled SEK 11.2 billion ( $€ 1.2$ billion), or $48.5 \%$ of total drug acquisition costs in Sweden 2006.

With the assumption of varying primary non-adherence rates for different age groups and different secondary nonadherence rates for varying types of drug therapies, the acquisition cost related to non-adherence totalled SEK 9.3 billion ( $€ 1.0$ billion), or $40.2 \%$ of the total drug acquisition costs.

When the assumption of varying primary and secondary non-adherence rates for a different number of dispensed drugs per patient was added to the model, the acquisition cost related to non-adherence totalled SEK 9.9 billion ( $€$ 1.1 billion), or $42.6 \%$ of the total drug acquisition costs.

Conclusions: Our estimate indicates that drug acquisition costs related to non-adherence represent a substantial proportion of the economic resources in the health care sector. A low rate of primary non-adherence, combined with a high rate of secondary non-adherence, contributes to a large degree of unnecessary medical spending. Thus, efforts of different types of interventions are needed to improve secondary adherence.
\end{abstract}

\section{Background}

Patients' non-adherence to drug therapy is a major problem in health care as this is associated with reduced health outcomes [1-3]. Patients' adherence to prescribers' drug therapy is essential for treatment efficacy,

\footnotetext{
* Correspondence: bo.hovstadius@pwc.se

1 eHealth Institute, Linnaeus University, Kalmar, Sweden

Full list of author information is available at the end of the article
}

patient safety, and healthcare costs. If patients do not follow the prescribed drug therapy the drugs will have no, or a reduced, effect. A large proportion of patients in all ages with different diseases do not adhere to therapy instructions. In developed countries, non-adherence to long-term therapy for chronic diseases averages 50\% [4-6], and in developing countries the non-adherence rate is even higher [5].

\section{Ciomed Central}

(c) 2011 Hovstadius and Petersson; licensee BioMed Central Ltd. This is an Open Access article distributed under the terms of the Creative Commons Attribution License (http://creativecommons.org/licenses/by/2.0), which permits unrestricted use, distribution, and reproduction in any medium, provided the original work is properly cited. 
There are several determinants as regards patients' non-adherence [4]: complexity of therapy [5], duration of therapy [5], characteristics of disease [5,7], adverse drug reactions $[5,8]$, cost of treatment $[5,7,9]$, characteristics of health service provision[5], interaction between prescriber and patient $[5,10]$, prescribers follow-up $[5,11]$, multiple providers $[5,10]$ socio-economic variables [5], multiple medication [10], the patients' own view of required therapy $[8,12,13]$ and unintended nonadherence [12]. The most common non-adherence refers to chronic under-use, i.e. patients use less medication than prescribed, or prematurely stop the therapy [5]. The World Health Organization (WHO) categorised the determinants of non-adherence into five dimensions: social and economic, health system-related, therapyrelated, condition-related, and patient-related [5].

Non-adherence is commonly divided into primary and secondary non-adherence. Irrespective of the cause, primary non-adherence represents the prescriptions the patient not fill at pharmacies [14,15] and secondary non-adherence represents the dispensed drugs that the patient not take as prescribed $[15,16]$.

The rate of non-adherence differs between different age groups. Generally, the rate of non-adherence decreases with a higher age $[7,8,11,12,17]$. There is a minor gender difference in non-adherence; the rate of non-adherence is slightly higher for women than for men $[8,18,19]$.

Non-adherence is a problem across all therapeutic areas $[5,20,21]$. However, variation in non-adherence can, to some extent, be explained by the type of drug or in terms of whether the patient's drug therapy is chronic or acute [22-25].

The use of multiple medication is a rational therapy for many patients, but it is also a well-known risk factor for patients' health as multiple medication is associated with adverse drug reactions, interactions and non-adherence to drug therapy [26], and the rate of non-adherence increases with an increasing number of drugs [27-35].

Cost-related non-adherence (CRNA) is a major determinant of non-adherence, $[18,36]$. Countries with the lowest out-of pocket costs for drugs also have the lowest average rate of CRNA [36]. Countries with no mandatory health insurance system also have large internal variations in CRNA $[9,17]$.

Non-adherence leads to poor health outcomes and high extra costs for society when filled drug prescriptions cannot produce an effect as they are not taken by the patient [37]. Non-adherence also represents a waste of substantial economic resources due to unnecessary drug sales [16]. In the majority of countries, the cost of wasted medication is shared between the patients and society.
With access to the Swedish prescribed drug register, it is possible to utilise patient-based data for an entire national population in order to analyse drug acquisition costs in terms of drug groups, age, gender, and multiple medication, without any sample, recall, or interview bias. With patient-based data on dispensed drugs, it is possible to shift the focus from the drug exposure of the total population, e.g. acquisition cost per inhabitant, to the drug exposure of the patients who have actually received different medications, e.g. acquisition cost per patient on the basis of a certain drug.

\section{Aim of the study}

To estimate the drug acquisition costs related to nonadherence to drug therapy in a national population.

\section{Methods}

To estimate the drug acquisition costs related to nonadherence to drug therapy in a national population, we studied the patient based data of all dispensed prescription drugs in the entire Swedish population during a 12month period 2006. This data was extracted from the Swedish prescribed drug register [38].

\section{The Swedish prescribed drug register}

The Swedish prescribed drug register is patient based and contains data for dispensed out-patient prescriptions at all Swedish pharmacies from July 1, 2005. The register is complete with regard to dispensed prescriptions. In 2006, dispensed out-patient prescriptions accounted for $82 \%$ of all defined daily doses (DDD), and the remaining $18 \%$ consisted of OTC sales and inpatient use in hospitals [38].

The registration is mandatory and the following data from the register was used in our study: number of patients, the dispensed drug (substance), number of dispensed prescription drugs per patient, the cost of the drug, DDD, number of DDD per patients, the date of dispensing, age, gender, and a unique identifier (personal identification number) of the patient.

The study population was comprised of all patients of all ages receiving one or more dispensed drugs during the 12-month study period that is, a total of, $6,161,673$ (3, 481, 371 women and 2, 680, 302 men), corresponding to $67.6 \%$ of the Swedish population [39].

The applied definition of drug was the chemical entity or substance comprising the fifth level in the WHO Anatomic, Therapeutic, Chemical (ATC) classification 2006. In the presentation, the drugs were categorized according to the second level of the ATC-classification.

All data processing was undertaken anonymously without the personal identification number. Only gender and age, originally embedded in the personal identification number, were recorded. The study population was 
stratified by gender and age (10-year classes). The results were compared to the number of individuals per gender and age group in the Swedish population.

In Sweden, prescriptions are valid for 12 months and the filling of one prescription usually covers consumption for a 3-month period [40].

\section{Adherence}

Adherence can be defined as "the extent to which the patient follows medical instructions" [5], or "the extent to which patient behaviour corresponds with recommendations from a health care provider" [5].

\section{Primary and secondary adherence}

Medical adherence is commonly divided into primary adherence (prescription being filled by patient) $[14,15,41]$ and secondary adherence (medication used as prescribed) $[15,16,41]$.

Adherence measurement options include drug claims data, interviews, surveys, pill counts and drug assays. The majority of adherence research has addressed secondary adherence of chronic therapies [42]. There exist a large number of varying measurements to estimate secondary adherence of long-term therapies from administrative data, including e.g. MRA, MPR, and PDC [43].

\section{A model to estimate the share of drug costs related to non- adherence}

In order to estimate the share of drug costs related to nonadherence, we constructed a model based on the patient data of all dispensed prescription drugs in the entire Swedish population during a 12 -month period, 2006. In the model, the total drug acquisition cost was successively adjusted for assumptions regarding different rates of primary non-adherence and secondary adherence, based on the patient's age, therapies, and the number of dispensed drugs per patient. As secondary non-adherence refers to the amount of prescribed drugs and not to the patients' filled prescriptions, the drug cost related to non-adherence is defined as the difference in cost between actual, filled prescriptions (primary adherence) and a calculated estimation of the total cost of the amount of drugs taken as prescribed (secondary adherence).

\section{Assumptions of non-adherence}

Based on two previous studies from Sweden, we applied a primary non-adherence rate of $3 \%$ (measured as nonfilled prescriptions at pharmacies) in the model [12,44]. The applied rate of primary non-adherence is also equivalent to the proportion of the population which did not fill a prescription during 2005 [18].

\section{Gender}

Generally, there is a slight gender difference in adherence $[8,19]$, but studies from Sweden have reported contradictory results $[12,18]$. Thus, no gender adjustment was implemented in our model.

\section{Age}

Based on previous studies $[7,11,12,17,20,45]$, we also adjusted our model for age difference in primary adherence. The highest rate of adherence is displayed for the elderly and children. The lowest adherence rate is displayed for young adults. Based on a Swedish study [18], we applied an age primary non-adherence rate of $2 \%$ for the age group $0-19,4 \%$ for $20-49,3 \%$ for $50-69$, and $2 \%$ for patients above 70 .

\section{Drug therapies}

In the model, we also adjusted for differences in the non-adherence rate between different drug therapies [23-25]. "Short-term" drugs were categorised as the ATC-groups in which the average $\mathrm{DDD} /$ patient during the year 2006 was below 200 DDD. In the model, we applied an assumed secondary non-adherence rate of $30 \%$ for "Short-term" drugs.

Continuing drug therapies were categorised as ATCgroups in which the average $\mathrm{DDD} /$ patient during a year was over 200 DDD. We applied an assumed secondary non-adherence rate of $50 \%$ for continuing drug therapies [4-6]. As certain drugs do not have established DDD, we established a third category: ATC-groups with no established DDD. We applied an assumed secondary non-adherence rate of $30 \%$ for ATC-groups with no established DDD.

\section{Multiple medication}

In the model, we also adjusted for differences in the secondary non-adherence rate between different numbers of dispensed drugs per patient. Multiple medication is commonly associated with increasing non-adherence [26-32] and, therefore, we assumed that the increase rate in dispensed DDD per patient (primary adherence) decreases with an increased number of prescribed drugs, as well as with an increased rate in ingested DDD per patient (secondary adherence). Due to the lack of information on the actual amount of prescribed drugs, the relation between prescribed and dispensed drugs, with an increasing number of drugs, is unknown. Primary non-adherence rates of $3-50 \%$ have been reported $[8,12,46]$. In our model, we applied the following assumptions of the increasing rate of secondary non-adherence with an increasing number of drugs: 1 to 4 dispensed drugs (DP1-4) per patient has a non-adherence rate of 30\%, DP5-9 40\%, DP10-14 50\%, and DP $\geq 1560 \%$.

In the result section, we excluded outliers: 7, 262 patients with more than 30 different dispensed drugs during 2006, corresponding to $0.12 \%$ of patients with dispensed drugs in Sweden in 2006. 
Microsoft Excel (version 5.1.26) was applied for analysis of data. The Regional Ethical Review Board in Linköping, Sweden, approved the study. The average exchange rate 2006 between Euro $(€)$ and Svensk krona (SEK): $1 €=9.25830$ SEK.

\section{Results}

Total acquisition cost of dispensed drugs

The total acquisition cost of dispensed drugs in Sweden was SEK 23.1 billion in 2006, women, SEK 12.4 and men, SEK 10.7 billion. The average acquisition cost of dispensed drugs per patient was SEK 3, 749, women, SEK 3, 575 and men, SEK 3, 974 (Table 1). Patients' total co-payment was SEK 5.8 billion or $25.2 \%$ of total acquisition cost of dispensed drugs 2006.

\section{Drug acquisition costs with regard to age}

Patients $<60$ years accounted for $50 \%$ of total drug acquisition costs, and patients $<70$ years accounted for $2 / 3$ of the total drug acquisition costs. The age groups with the largest proportion of the total costs were 69$69,50-59$, and $70-79$ years, with $19.8,17.2$, and $17.2 \%$, respectively.

The average drug acquisition cost per patient increased with an increasing age, from SEK 952 (SEK 736 for women and SEK 1, 146 for men) in the age group $0-9$, to a peak in the age group $80-89$, with SEK 6,721 (6, 378 for women and 7, 289 for men). In the age group above 90 years, the drug acquisition cost per patient decreased to a level comparable to the age group 60-69 years (Table 1).

\section{Drug acquisition costs with regard to drug therapy}

The 28 ATC-groups, of a total of 86, with a DDD per patient per year above 200, were categorised as a continuing drug therapy. Continuing drug therapies corresponded to $74.8 \%$ of all dispensed DDD and $59.6 \%$ of the cost of all dispensed drugs 2006.

The 43 ATC-groups with a DDD per patient per year below 200 were categorised as "short-term" drug therapy. "Short-term" therapy ATC-groups corresponded to $25.2 \%$ of all dispensed DDD and $37.4 \%$ of the cost of all dispensed drugs in Sweden 2006.

The remaining 15 ATC-groups have no established DDD and corresponded to $3.0 \%$ of the total acquisition cost of dispensed drugs.

The 7 ATC-groups with prevalence in the total population above $10 \%$ were to be found in both continuing and short-term drug therapies. The ATC-groups with an acquisition cost above SEK one billion were, with one exception, all categorised as continuing therapy.

Drug acquisition costs with regard to multiple medication The drug acquisition costs for patients with DP $\geq 5$ represented $78.8 \%$ of the total drug acquisition costs, patients with DP $\geq 10$ and DP $\geq 15,46.3$, and $23.2 \%$, respectively.

For patients with $\mathrm{DP} \geq 5, \mathrm{DP} \geq 10$, and $\mathrm{DP} \geq 15$, the publically financed drug costs represented 80.2, 86.1, and $89.7 \%$, respectively (Figure 1 ).

The average acquisition cost per patient displayed a near linear relationship with the numbers of dispensed drugs per patient, from an average of SEK 527 for patients with one drug, to SEK 37, 221 for patients with 30 different drugs, women, SEK 429 to SEK 35, 276, and men, SEK 634 to SEK 41, 910.

\section{Estimates of the drug acquisition costs related to non- adherence}

With an assumed primary non-adherence rate for Sweden of $3 \%$, and a secondary non-adherence rate of $50 \%$, the drug acquisition cost related to non-adherence totals

Table 1 Number of individuals, acquisition cost, and acquisition cost per individual in Sweden 2006.

\begin{tabular}{|c|c|c|c|c|c|c|c|c|c|}
\hline \multirow[b]{2}{*}{ Age group } & \multicolumn{3}{|c|}{ Individuals } & \multicolumn{3}{|c|}{$\begin{array}{l}\text { Acq cost } \\
\left({ }^{*} \text { million SEK) }\right.\end{array}$} & \multicolumn{3}{|c|}{ Acq cost/individual } \\
\hline & All & Women & Men & All & Women & Men & All & Women & Men \\
\hline $0-9$ & 556,818 & 263,385 & 293,433 & 530 & 194 & 336 & 952 & 736 & 1,146 \\
\hline $10-19$ & 585,481 & 341,063 & 244,418 & 1,103 & 473 & 630 & 1,884 & 1,388 & 2,577 \\
\hline $20-29$ & 650,272 & 418,256 & 232,016 & 1,162 & 667 & 494 & 1,786 & 1,596 & 2,129 \\
\hline $30-39$ & 772,667 & 456,855 & 315,812 & 2, 021 & 1,186 & 834 & 2,615 & 2,596 & 2,642 \\
\hline $40-49$ & 797,753 & 446,757 & 350,996 & 2,755 & 1,514 & 1,241 & 3,453 & 3,390 & 3,534 \\
\hline $50-59$ & 905,910 & 489,752 & 416,158 & 3,983 & 2,134 & 1,849 & 4, 397 & 4,358 & 4,442 \\
\hline $60-69$ & 831,432 & 436,085 & 395,347 & 4,566 & 2,354 & 2,212 & 5,492 & 5,399 & 5,594 \\
\hline $70-79$ & 598,583 & 332,601 & 265,982 & 3,966 & 2,092 & 1,874 & 6,626 & 6,290 & 7,046 \\
\hline 80-89 & 392,433 & 244,720 & 147,713 & 2,638 & 1,561 & 1, 077 & 6,721 & 6,378 & 7,289 \\
\hline$\geq 90$ & 70,324 & 51,897 & 18,427 & 375 & 269 & 105 & 5,326 & 5,190 & 5,709 \\
\hline Total & $6,161,673$ & $3,481,371$ & $2,680,302$ & 23, 098 & 12,446 & 10,651 & 3,749 & 3,575 & 3,974 \\
\hline
\end{tabular}

Number of individuals, acquisition cost (Acq cost), and acquisition cost per individual for all, women, and men, for different age groups in Sweden 2006. 


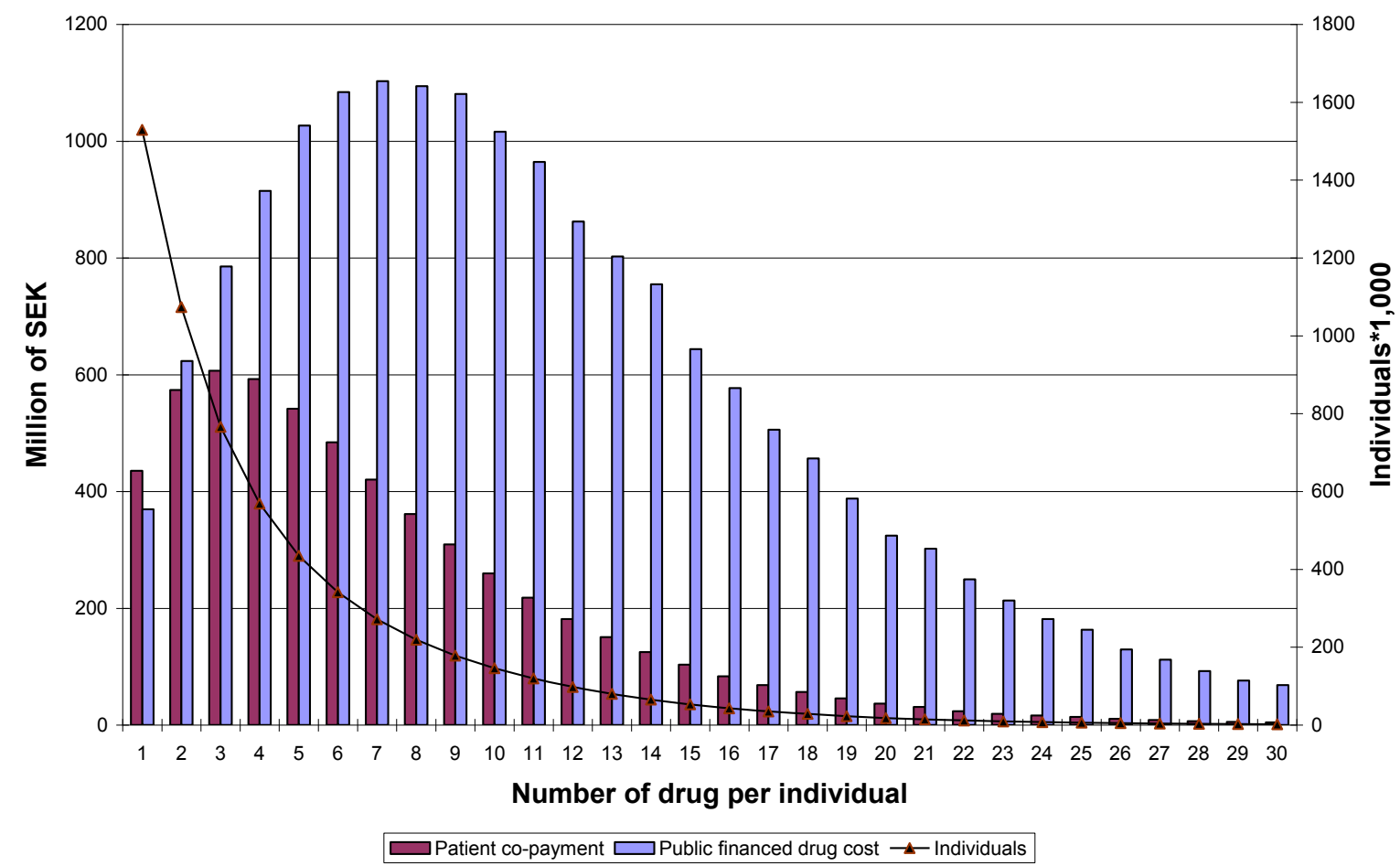

Figure 1 Number of patients, public financed drug cost and patient co-payment in Sweden 2006. Number of patients, total amount of public financed drug cost and patient co-payment for patient with 1 to 30 different dispensed drugs in Sweden 2006.

SEK 11, 219 million, or $48.5 \%$ of total drug acquisition costs in Sweden 2006 (Table 2).

With the assumption of varying secondary non-adherence rates for different types of drug therapies applied in the model, the acquisition cost related to non-adherence amounted to SEK 9, 290 million, or 40.1\% of total drug acquisition costs (Table 2).

With the assumption of varying primary non-adherence rates for the different age groups applied in the model, the acquisition cost related to non-adherence amounted to SEK 11, 200 million, or $48.4 \%$ of total drug acquisition costs (Table 2).

With the assumption of both different primary nonadherence rates for different age groups, and different secondary non-adherence rates for varying types of drug therapies applied in the model, the acquisition costs related to non-adherence totalled SEK 9, 268 million, or $40.0 \%$ of total drug acquisition costs (Table 2).

Finally, when assumptions of different non-adherence rates for an increasing number of drugs were applied in the model, the acquisition costs related to non-adherence totalled SEK 9, 855 million, or $42.6 \%$ of total drug acquisition costs (Table 3 ).

\section{Discussion}

There exists an "enormous amount of quantitative research" concerning medical adherence, but there is no golden standard for measurement [4] and studies of medical adherence vary widely in terminology, definitions and methods $[47,48]$. Both primary and secondary non-adherence are problems for health care across all therapeutic areas, but the majority of the adherence research has referred to secondary non-adherence and to chronic therapies [21,42]. In 2003, World Health Organisation published "Adherence to long term therapies: evidence for action", which included specific reviews of non-adherence in therapies for asthma, cancer, depression, diabetes, epilepsy, hypertension, tuberculosis [5]. Subsequently, comparing studies of secondary adherence estimates for hypertension, hyperthyroid, type 2 diabetes, seizure disorders, hypercholesterolemia, osteoporosis, and gout [20] and secondary adherence estimate for prostaglandin analogs, statins, bisphosphonates, oral antidiabetics, angiotensin II receptor blockers and overactive bladder medications have being presented [21]. There are also a large number of specific studies and reviews of adherence for specific medical condition e.g. diabetes, hypertensions and dyslipidaemia [49] osteoporosis [50], anticancer treatment [51], HIV [52] and mental disorder [53], etc. The reported results vary widely depending on the disease, study setting and measurements.

As direct measurement of medication consumption is usually not feasible, refill adherence has been applied as an 
Table 2 Drug acquisition costs related to non-adherence with varying therapies and ages in Sweden in 2006.

\begin{tabular}{|c|c|c|c|c|c|c|c|c|c|}
\hline \multirow[t]{2}{*}{ Age -Therapy } & \multicolumn{2}{|c|}{ DDD } & \multicolumn{2}{|c|}{ Acq. Cost } & \multirow{2}{*}{$\begin{array}{l}\text { Rate of } \\
\text { PNA }\end{array}$} & \multirow{2}{*}{$\begin{array}{l}\text { Cost of } \\
\text { prescribe drugs }\end{array}$} & \multirow{2}{*}{$\begin{array}{l}\text { Rate of } \\
\text { SNA }\end{array}$} & \multicolumn{2}{|c|}{ Acq. Cost related to NA } \\
\hline & ${ }^{*}$ million & $\%$ & million SEK & $\%$ & & & & million SEK & $\%$ of Acq cost \\
\hline All & 5253 & 100 & 23154 & 100 & 3 & 23870 & 50 & 11219 & 48,5 \\
\hline \multicolumn{10}{|l|}{ Therapy: } \\
\hline Continuing & 3927 & 74,8 & 13798 & 59,6 & 3 & 14225 & 50 & 6686 & 48,5 \\
\hline short-term & 1326 & 25,2 & 8659 & 37,4 & 3 & 8927 & 30 & 2410 & 27,8 \\
\hline (no DDD) & & & 697 & 3,0 & 3 & 718 & 30 & 194 & 27,8 \\
\hline Total & 5253 & 100 & 23154 & 100,0 & & 23870 & & 9290 & 40,1 \\
\hline \multicolumn{10}{|l|}{ Age: } \\
\hline $0-19$ & 241 & 4,6 & 1641 & 7,1 & 2 & 1675 & 50 & 804 & 49,0 \\
\hline $20-49$ & 976 & 18,6 & 5966 & 25,8 & 4 & 6215 & 50 & 2859 & 47,9 \\
\hline $50-69$ & 1894 & 36,1 & 8568 & 37,0 & 3 & 8833 & 50 & 4151 & 48,5 \\
\hline $70-$ & 2142 & 40,8 & 6979 & 30,1 & 2 & 7122 & 50 & 3418 & 49,0 \\
\hline Total & 5253 & 100 & 23154 & 100,0 & & 239844 & 50 & 11232 & 48,5 \\
\hline \multicolumn{10}{|l|}{ Therapy and age } \\
\hline \multicolumn{10}{|l|}{ Continuing } \\
\hline 0-19 & 179 & & 651 & 2,8 & 2 & 664 & 50 & 319 & 49,0 \\
\hline $20-49$ & 696 & & 3542 & 15,3 & 4 & 3689 & 50 & 1697 & 47,9 \\
\hline $50-69$ & 1407 & & 5267 & 22,7 & 3 & 5430 & 50 & 2552 & 48,5 \\
\hline $70-$ & 1645 & & 4339 & 18,7 & 2 & 4428 & 50 & 2125 & 49,0 \\
\hline \multicolumn{10}{|l|}{ Short-term } \\
\hline 0-19 & 63 & & 937 & 4,0 & 2 & 956 & 30 & 268 & 28,6 \\
\hline $20-49$ & 279 & & 2233 & 9,6 & 4 & 2326 & 30 & 605 & 27,1 \\
\hline $50-69$ & 487 & & 2989 & 12,9 & 3 & 3081 & 30 & 832 & 27,8 \\
\hline $70-$ & 497 & & 2501 & 10,8 & 2 & 2552 & 30 & 715 & 28,6 \\
\hline \multicolumn{10}{|l|}{ no DDD } \\
\hline 0-19 & & & 53 & 0,2 & 2 & 54 & 30 & 15 & 28,6 \\
\hline $20-49$ & & & 192 & 0,8 & 4 & 200 & 30 & 52 & 27,1 \\
\hline $50-69$ & & & 313 & 1,3 & 3 & 322 & 30 & 87 & 27,8 \\
\hline 70- & & & 139 & 0,6 & 2 & 142 & 30 & 40 & 28,6 \\
\hline Total & 5253 & 0 & 23154 & 100,0 & & 23844 & & 9306 & 40,2 \\
\hline
\end{tabular}

DDD, acquisition costs for dispensed drug (Acq cost), rate of primary non-adherence (PNA), estimated acquisition costs for prescribed drugs, rate of secondary non-adherence (SNA) and drug acquisition costs related to non-adherence (NA) for individuals with varying therapies and ages in Sweden in 2006.

estimate of adherence in population-based studies [54]. However, when medication adherence is estimated from e. g. pharmacy claims databases, the estimates are substantially inflated as non-adherence and early non-persistent patients are largely not included in the estimations [55]. Various studies have reported primary adherence rates of nearly $50 \%$ in psoriasis [46], 31.4\% in diabetes [14], 24.3\% in hypertension [56], and $19.9 \%$ in antidepressants [57]. In addition, pharmacy claims databases are not feasible for estimating the secondary adherence (medication taken as prescribed) of "short-term" or "acute" therapies, e.g. all 11 measurements of refill adherence reported by Hess et al are relevant only to secondary adherence for chronic/continuing therapies [43].

\section{The basic assumptions of non-adherence}

Total drug acquisition costs represent between 10-20\% of health care expenditure in developed countries [58].
The Swedish rate of $13 \%$ is the approximate average within Europe [18]. Consequently, our results appear to be relevant for comparison with the results from other developed countries.

In Sweden, total drug acquisition costs show no clear age profile. The fact that the age group 0-69 years accounted for nearly $70 \%$ of costs indicates that the elderly were not the most interesting age group from an economic perspective. Drug acquisition costs per patient increased with increasing age, and reached a peak in the age group 70-89. Women represented somewhat more than $50 \%$ of total drug acquisition costs, but men had a higher average cost per patient than women in all age groups.

Continuing drug therapies represented approximately $60 \%$ of total drug acquisition costs and were, therefore, the dominant therapy in terms of costs related to nonadherence. "Short-term" drug therapies represented 
Table 3 Drug acquisition costs related to non-adherence with different number of dispensed drugs in Sweden 2006.

\begin{tabular}{|c|c|c|c|c|c|c|c|c|c|c|c|}
\hline \multirow[b]{2}{*}{ Therapy } & \multirow[b]{2}{*}{ Age } & \multirow[b]{2}{*}{ DP } & \multicolumn{2}{|c|}{ DDD } & \multicolumn{2}{|c|}{ Acq cost } & \multirow{2}{*}{$\begin{array}{l}\text { PNA } \\
\text { rate }\end{array}$} & \multirow{2}{*}{$\begin{array}{l}\text { Prescribed } \\
\text { drug cost }\end{array}$} & \multirow{2}{*}{$\begin{array}{l}\text { SNA } \\
\text { rate }\end{array}$} & \multirow{2}{*}{$\frac{\text { Cost related }}{\text { million }}$} & \multirow{2}{*}{$\begin{array}{c}\text { non-adherence } \\
\%\end{array}$} \\
\hline & & & million & $\%$ & million & $\%$ & & & & & \\
\hline \multirow[t]{16}{*}{$\overline{\text { Conti. }}$} & $0-19$ & DP1-4 & 106 & 2 & 329 & 1,4 & 3 & 339 & 40 & 126 & 38,1 \\
\hline & & DP5-9 & 56 & 1,1 & 224 & 1 & 2 & 229 & 50 & 110 & 49,0 \\
\hline & & DP10-14 & 13 & 0,2 & 61 & 0,3 & 2 & 63 & 50 & 30 & 49,0 \\
\hline & & DP15- & 4 & 0,1 & 36 & 0,2 & 2 & 37 & 60 & 21 & 59,2 \\
\hline & $20-49$ & DP1-4 & 273 & 5,2 & 1151 & 5 & 4 & 1199 & 40 & 432 & 37,5 \\
\hline & & DP5-9 & 236 & 4,5 & 1301 & 5,6 & 4 & 1356 & 50 & 624 & 47,9 \\
\hline & & DP10-14 & 106 & 2 & 610 & 2,6 & 4 & 636 & 50 & 292 & 47,9 \\
\hline & & DP15- & 81 & 1,5 & 479 & 2,1 & 4 & 499 & 60 & 279 & 58,3 \\
\hline & $50-69$ & DP1-4 & 250 & 4,8 & 855 & 3,7 & 3 & 882 & 40 & 326 & 38,1 \\
\hline & & DP5-9 & 532 & 10,1 & 1820 & 7,9 & 3 & 1876 & 50 & 882 & 48,5 \\
\hline & & DP10-14 & 338 & 6,4 & 1286 & 5,6 & 3 & 1326 & 50 & 623 & 48,5 \\
\hline & & DP15- & 288 & 5,5 & 1305 & 5,6 & 3 & 1346 & 60 & 767 & 58,8 \\
\hline & 70- & DP1-4 & 118 & 2,3 & 328 & 1,4 & 2 & 335 & 40 & 127 & 38,8 \\
\hline & & DP5-9 & 516 & 9,8 & 1276 & 5,5 & 2 & 1302 & 50 & 625 & 49,0 \\
\hline & & DP10-14 & 525 & 10 & 1337 & 5,8 & 2 & 1364 & 50 & 655 & 49,0 \\
\hline & & DP15- & 485 & 9,2 & 1398 & 6 & 2 & 1426 & 60 & 827 & 59,2 \\
\hline Short- & 0-19 & DP1-4 & 36 & 0,7 & 550 & 2,3 & 2 & 560 & 20 & 101 & 18,3 \\
\hline \multirow[t]{15}{*}{ term } & & DP5-9 & 20 & 0,4 & 263 & 1,1 & 2 & 268 & 30 & 75 & 28,5 \\
\hline & & DP10-14 & 5 & 0,1 & 87 & 0,4 & 2 & 88 & 40 & 33 & 38,4 \\
\hline & & DP15- & 2 & 0 & 38 & 0,2 & 2 & 39 & 50 & 19 & 49,3 \\
\hline & $20-49$ & DP1-4 & 97 & 1,8 & 796 & 3,4 & 4 & 830 & 20 & 133 & 16,7 \\
\hline & & DP5-9 & 98 & 1,8 & 764 & 3,3 & 4 & 795 & 30 & 207 & 27,1 \\
\hline & & DP10-14 & 46 & 0,9 & 363 & 1,5 & 4 & 379 & 40 & 136 & 37,6 \\
\hline & & DP15- & 39 & 0,7 & 310 & 1,3 & 4 & 323 & 50 & 149 & 47,9 \\
\hline & $50-69$ & DP1-4 & 94 & 1,8 & 562 & 2,5 & 3 & 579 & 20 & 98 & 17,5 \\
\hline & & DP5-9 & 169 & 3,2 & 1000 & 4,3 & 3 & 1031 & 30 & 278 & 27,8 \\
\hline & & DP10-14 & 113 & 2,2 & 692 & 2,9 & 3 & 714 & 40 & 264 & 38,2 \\
\hline & & DP15- & 111 & 2,2 & 734 & 3,2 & 3 & 756 & 50 & 355 & 48,4 \\
\hline & $70-$ & DP1-4 & 39 & 0,7 & 191 & 0,8 & 2 & 196 & 20 & 35 & 18,5 \\
\hline & & DP5-9 & 142 & 2,8 & 679 & 2,9 & 2 & 693 & 30 & 194 & 28,6 \\
\hline & & DP10-14 & 155 & 3 & 763 & 3,3 & 2 & 778 & 40 & 296 & 38,7 \\
\hline & & DP15- & 161 & 3 & 868 & 3,8 & 2 & 886 & 50 & 425 & 49,0 \\
\hline No DDD & & & 0 & 0 & 697 & 3 & & 718 & 50 & 309 & 44,3 \\
\hline All & & & 5254 & 100 & 23153 & 99,9 & & 23848 & & 9855 & 42,6 \\
\hline
\end{tabular}

DDD, acquisition costs for dispensed drugs (Acq cost), rate of primary non-adherence (PNA), estimated acquisition costs for prescribed drugs, rate of secondary non-adherence (SNA)and drug acquisition costs related to non-adherence for individuals with varying therapies, age and different number of dispensed drugs in Sweden in 2006

slightly more than one third of total acquisition costs, and had, therefore, a minor impact on total drug costs related to non-adherence.

Multiple medication is a common cause of non-adherence and the rate of non-adherence is assumed to increase with the number of drugs per patient [27-32]. However, we have not found any studies that have assessed, in detail, the relationship between non-adherence and an increasing number of drugs. Therefore, we made the rough assumption, that patients with a large number of different drugs have an above average nonadherence rate, and patients with few drugs have a below average non-adherence rate. However, patients with five or more drugs account for nearly $80 \%$ of total drug acquisition costs and have, consequently, a substantial impact on total acquisition costs related to nonadherence.

\section{Causes of primary and secondary non-adherence}

That patients do not take their medication as prescribed (secondary non-adherence) might be due to several circumstances, e.g. the patients have experienced an adverse drug reaction, patients do not feel that they need the drugs, or they just forget to ingest the drugs. Secondary adherence to drug therapy also depends on the patient's age, gender, disease burden, the complexity and duration of the drug therapy, as well as on the 
quality of the interaction between patient and prescriber. Furthermore, secondary adherence depends on whether the prescriber follows-up therapy, if the patient feels safe with the drugs, or has multiple providers or multiple medication. Even if differences in the rate of secondary adherence might exist between countries, the causes of secondary adherence are assumed to be universal. Many characteristics of secondary adherence may also have the subsequent effect that patients do not fill their prescriptions (primary non-adherence).

\section{Costs related to non-adherence}

A factor which, theoretically, is exclusive to primary adherence, is cost-related non-adherence (CRNA), and in many countries CRNA is one of the largest determinants of non-adherence. Sweden and The Netherlands display a high rate of primary adherence compared to most other countries [18,36]. Probably, these countries' low CRNA rates contribute to explaining the high rates of primary adherence. In the US, the average CRNA is $20 \%$ or more [17], but for elderly and uninsured adults, the rate is estimated to be $30 \%$ and $40 \%$, respectively $[7,9,17]$.

The low rate of CRNA in Sweden (1\%) can probably be explained by the comprehensive drug reimbursement system. In excess of a patient co-payment ceiling of SEK 1,800 (€195), all additional fill of prescriptions are without charge. It could be expected that above this cost ceiling, the patient have no economic incentive to refrain from having the prescriptions filled. Due to the perceived insistence of the health care sector, the patient might feel that filling the prescription is the easiest thing to do, even if the patient, for a number of reasons, does not intend to take the medication.

\section{The relationship between primary and secondary non- adherence}

Both primary and secondary non-adherence have, independent of each other, an impact on the estimates of drug acquisition costs related to non-adherence, but we can also assume that primary non-adherence and secondary non-adherence impact each other. Without a comprehensive drug reimbursement system, a high rate of secondary non-adherence probably also impacts the rate of primary non-adherence.

A low rate of primary non-adherence combined with a high rate of secondary non-adherence leads to large amounts of unnecessary drug costs, and a high rate of primary non-adherence, combined with a low rate of secondary non-adherence leads to small amounts of, or no, unnecessary drug costs. Consequently, in order to minimize wasteful medical spending, the difference between primary non-adherence and secondary nonadherence should be as limited as possible.

In a public health perspective, the largest cost for the society is untreated diseases and not unnecessary drug sales [59]. Interventions to increase the rate of primary non-adherence to achieve smaller differences compared with the rate of secondary adherence can, therefore, comprise a sub optimising measure, if such intervention also negatively impacts the rate of secondary nonadherence.

\section{The validity of the estimate of total drug acquisition costs due to non-adherence}

In our estimates, non-adherence is determined by varying assumptions regarding the secondary nonadherence rate for age, therapy, and multiple medication. The main determinant is the non-adherence rate of different therapies. However, the proportion of costs referring to non-adherence is approximately $40 \%$ of total drug acquisition costs, largely irrespective of any change in the basic assumptions in terms of the non-adherence rate of different therapies. An assumed higher secondary non-adherence rate for "short-term" drug therapies (from $30 \%$ to $40 \%$ ) results in a minor increase in total costs related to non-adherence (from 40 to $44 \%$ ). If, at the same time, the threshold value for continuing drug therapy is raised (from 200 to 300 DDD per patient per year), total costs related to nonadherence, instead, increase marginally (from 40 to $41 \%)$.

The most common non-adherence is for chronic under-use, i.e. patients use less medication than prescribed, or prematurely stop therapy [5], and therefore, we have assumed that the volume of drugs within the non-adherence has no effect on health outcomes. However, it could be assumed that certain amounts of the ingested drugs, but which are not taken in full according to the prescription or recommendation might have some positive effect on the health outcome. This assumption will not change the estimate of drug acquisition costs related to non-adherence, but can be seen as an argument that the definition of non-adherence to drug therapies might overestimate the volume of unnecessary drug sales.

\section{The relevance of total drug acquisition costs due to non- adherence}

That patients' non-adherence to therapy leads to high extra costs for society in terms of poor health for patients [37], and to the fact that as approximately $40 \%$ of the total drug acquisition costs is related to patients' non-adherence to drug therapies, this must be seen to comprise a highly non-satisfactory situation. As the amount of total drug acquisition costs represented approximately a third of the total cost of primary care in Sweden in 2006 [60], this should also be considered by the health care stakeholders as being highly relevant in an economic perspective. 


\section{Implications for health care}

Non-adherence to drug therapies represents a waste of large amounts of economic resources, both for the patients and for society. A reduction of drug acquisition costs related to non-adherence should be achieved by interventions focused on improving secondary adherence, e.g. active handling to change patient behaviour, reduce side effects and therapy complexity, improving the provision of health services, and improving the interaction between health care personnel and patients.

Interventions should be directed to patients or to providers, or health care managers. Sadly, long term patient-focused intervention has shown to have no substantial effect on adherence [5], e.g. attempts with different types of patient reminding-systems for filling of prescriptions have shown no significant effects [61-63], but the routine follow-up by the prescriber has displayed significant increasing adherence $[11,64]$. An intervention directed to prescribers to decrease the complexity of the drug therapy, e.g. a change to one dosage a day instead of two, has also improved adherence [5]. Another intervention that have been suggested is the introduction of financial incentives or other rewards for patients who adhere to therapy [65].

A low rate of primary non-adherence not combined with a low rate of secondary non-adherence results in major costs for patients and society in terms of unnecessary drug sales. A reduction of the cost related to nonadherence can, therefore, also be achieved by interventions aimed at increasing primary non-adherence, e.g. modifying the drug reimbursement system to better correspond with patients' secondary non-adherence.

\section{Strengths and limitations}

The study is based on patient data on pharmacy claims without any sample, recall or interview bias for all patients with dispensed drugs in an entire national population. The study combined actual pharmacy claims data with general assumptions based on previous studies of different non-adherence rates for patients in different age groups, drug therapies, and with a varying number of dispensed drugs. A limitation is that the assumptions made in the present study are based on previous studies that often only focus on adherence to one specific long-term medical therapy. Results from previous studies concerning the nonadherence rate for short-term therapies, patients' age, and number of dispensed drugs per patient are often only qualitative. Consequently, certain of the assumptions about varying non-adherence rates in the present study are relatively rough. Furthermore, the register includes all dispensed prescriptions drugs but has no information regarding other types of drugs e.g. OTCdrugs and CAM. Nor has the register any information about the volume and the distribution of prescribed drugs that are not filled, nor as regards the rate of filled drug not taken as prescribed

\section{Conclusions}

Our estimate indicates that drug acquisition costs related to non-adherence represent a substantial proportion of the economic resources in the health care sector. A low rate of primary non-adherence, combined with a high rate of secondary non-adherence, contributes to a large amount of unnecessary medical spending. Thus, efforts of different types of interventions are needed to improve secondary adherence.

\section{Acknowledgements}

The study was funded by grants from the National Corporation of Pharmacies (Apoteket AB). The study was designed and conducted independent of the funding organisation. We express our appreciation to Andrejs Leimanis of The Swedish National Board for Health and Welfare for assistance with data material from the Swedish prescribed drug register and to Karl Hovstadius, Uppsala University, as regards statistical procedures.

\section{Author details}

'eHealth Institute, Linnaeus University, Kalmar, Sweden. ${ }^{2}$ School of Natural Sciences, Linnaeus University, Kalmar, Sweden. ${ }^{3}$ School of Health and Caring Sciences, Linnaeus University, Kalmar, Sweden.

\section{Authors' contributions}

Both authors participated in the design of the study and the discussion of the findings. $\mathrm{BH}$ executed the data management and $\mathrm{BH}$ drafted the

manuscript. GP revised the manuscript. Both authors read and approved the final manuscript.

\section{Competing interests}

The authors declare that they have no competing interests.

Received: 17 February 2011 Accepted: 28 November 2011 Published: 28 November 2011

\section{References}

1. Simpson SH, Eurich DT, Majumdar SR, Padwal RS, Tsuyuki RT, Varney J, Johnson JA: A meta-analysis of the association between adherence to drug therapy and mortality. BMJ 2006, 333(7557):15.

2. Sokol MC, McGuigan KA, Verbrugge RR, Epstein RS: Impact of medication adherence on hospitalization risk and healthcare cost. Med Care 2005, 43(6):521-530.

3. Rasmussen JN, Chong A, Alter DA: Relationship between adherence to evidence-based pharmacotherapy and long-term mortality after acute myocardial infarction. JAMA 2007, 297(2):177-186.

4. Vermeire $E$, Hearnshaw $H$, Van Royen $P$, Denekens J: Patient adherence to treatment: three decades of research. A comprehensive review. J Clin Pharm Ther 2001, 26(5):331-342.

5. Adherence to long-term therapies: evidence for action. World Health Organization; 2003

6. Dunbar-Jacob J, Mortimer-Stephens MK: Treatment adherence in chronic disease. J Clin Epidemiol 2001, 54(Suppl 1):S57-60.

7. Briesacher BA, Gurwitz JH, Soumerai SB: Patients at-risk for cost-related medication nonadherence: a review of the literature. J Gen Intern Med 2007, 22(6):864-871.

8. Kennedy J, Tuleu I, Mackay K: Unfilled prescriptions of medicare beneficiaries: prevalence, reasons, and types of medicines prescribed. $J$ Manag Care Pharm 2008, 14(6):553-560.

9. Piette JD, Wagner TH, Potter MB, Schillinger D: Health insurance status, cost-related medication underuse, and outcomes among diabetes patients in three systems of care. Med Care 2004, 42(2):102-109. 
10. Vik SA, Maxwell CJ, Hogan DB: Measurement, correlates, and health outcomes of medication adherence among seniors. Ann Pharmacother 2004, 38(2):303-312.

11. Bardel A, Wallander MA, Svardsudd K: Factors associated with adherence to drug therapy: a population-based study. Eur J Clin Pharmacol 2007, 63(3):307-314.

12. Ekedahl A, Mansson N: Unclaimed prescriptions after automated prescription transmittals to pharmacies. Pharm World Sci 2004, 26(1):26-31.

13. Williams AF, Manias E, Walker R: Adherence to multiple, prescribed medications in diabetic kidney disease: A qualitative study of consumers' and health professionals' perspectives. Int J Nurs Stud 2008, 45(12):1742-1756.

14. Fischer MA, Stedman MR, Lii J, Vogeli C, Shrank WH, Brookhart MA, Weissman JS: Primary medication non-adherence: analysis of 195, 930 electronic prescriptions. J Gen Intern Med 25(4):284-290.

15. Karter AJ, Parker MM, Moffet HH, Ahmed AT, Schmittdiel JA, Selby JV: New prescription medication gaps: a comprehensive measure of adherence to new prescriptions. Health Serv Res 2009, 44(5 Pt 1):1640-1661.

16. Bewley A, Page B: Maximizing patient adherence for optimal outcomes in psoriasis. J Eur Acad Dermato/ Venereo/ 25(Suppl 4):9-14

17. Kennedy J, Morgan S: Cost-related prescription nonadherence in the United States and Canada: a system-level comparison using the 2007 International Health Policy Survey in Seven Countries. Clin Ther 2009, 31(1):213-219.

18. Socialstyrelsen: Folkhälsorapport 2009 [Public Health report 2009] Swedish. Stockholm, Sweden; 2009.

19. Wilson IB, Rogers WH, Chang H, Safran DG: Cost-related skipping of medications and other treatments among Medicare beneficiaries between 1998 and 2000. Results of a national study. J Gen Intern Med 2005, 20(8):715-720.

20. Briesacher BA, Andrade SE, Fouayzi H, Chan KA: Comparison of drug adherence rates among patients with seven different medical conditions. Pharmacotherapy 2008, 28(4):437-443.

21. Yeaw J, Benner JS, Walt JG, Sian S, Smith DB: Comparing adherence and persistence across 6 chronic medication classes. J Manag Care Pharm 2009, 15(9):728-740.

22. Lee RD, Bergman U: Studies of Drug Utilization. In Pharmacoepidemiology.. Fourth edition. Edited by: Strom BL. Chichester: John Wiley 2005:401-417.

23. Osterberg L, Blaschke T: Adherence to medication. N Engl J Med 2005, 353(5):487-497.

24. Kardas P: Patient compliance with antibiotic treatment for respiratory tract infections. J Antimicrob Chemother 2002, 49(6):897-903.

25. Wright H, Forbes D, Graham H: Primary compliance with medication prescribed for paediatric patients discharged from a regional hospital. $J$ Paediatr Child Health 2003, 39(8):611-612.

26. Salazar JA, Poon I, Nair M: Clinical consequences of polypharmacy in elderly: expect the unexpected, think the unthinkable. Expert Opin Drug Saf 2007, 6(6):695-704

27. Gorard DA: Escalating polypharmacy. QJM 2006, 99(11):797-800.

28. Bjerrum L, Rosholm JU, Hallas J, Kragstrup J: Methods for estimating the occurrence of polypharmacy by means of a prescription database. Eur $J$ Clin Pharmacol 1997, 53(1):7-11.

29. Colley CA, Lucas LM: Polypharmacy: the cure becomes the disease. J Gen Intern Med 1993, 8(5):278-283.

30. Fincke BG, Snyder K, Cantillon C, Gaehde S, Standring P, Fiore L, Brophy M, Gagnon DR: Three complementary definitions of polypharmacy: methods, application and comparison of findings in a large prescription database. Pharmacoepidemiol Drug Saf 2005, 14(2):121-128.

31. Rollason $V$, Vogt $N$ : Reduction of polypharmacy in the elderly: a systematic review of the role of the pharmacist. Drugs Aging 2003, 20(11):817-832.

32. Bloom BS: Daily regimen and compliance with treatment. BMJ 2001 323(7314):647.

33. Balkrishnan R: Predictors of medication adherence in the elderly. Clin Ther 1998, 20(4):764-771.

34. Barat I, Andreasen F, Damsgaard EM: Drug therapy in the elderly: what doctors believe and patients actually do. Br J Clin Pharmacol 2001, 51(6):615-622

35. Cramer JA: A systematic review of adherence with medications for diabetes. Diabetes Care 2004, 27(5):1218-1224.
36. Kemp A, Roughead E, Preen D, Glover J, Semmens J: Determinants of selfreported medicine underuse due to cost: a comparison of seven countries. J Health Serv Res Policy 15(2):106-114.

37. Krigsman K, Melander A, Carlsten A, Ekedahl A, Nilsson JL: Refill nonadherence to repeat prescriptions leads to treatment gaps or to high extra costs. Pharm World Sci 2007, 29(1):19-24

38. Wettermark B, Hammar N, MichaelFored C, Leimanis A, Otterblad Olausson P, Bergman U, Persson I, Sundstrom A, Westerholm B, Rosen M: The new Swedish Prescribed Drug Register-opportunities for pharmacoepidemiological research and experience from the first six months. Pharmacoepidemiol Drug Saf 2007, 16(7):726-735.

39. Hovstadius B, Astrand B, Petersson G: Dispensed drugs and multiple medications in the Swedish population: an individual-based register study. BMC Clin Pharmacol 2009, 9(1):11.

40. Astrand B, Hovstadius B, Antonov K, Petersson G: The Swedish national pharmacy register. Stud Health Technol Inform 2007, 129:345-349.

41. Rashid A: Do patients cash prescriptions? Br Med J (Clin Res Ed) 1982, 284(6308):24-26.

42. Jackevicius CA, Li P, Tu JV: Prevalence, predictors, and outcomes of primary nonadherence after acute myocardial infarction. Circulation 2008, 117(8):1028-1036.

43. Hess LM, Raebel MA, Conner DA, Malone DC: Measurement of adherence in pharmacy administrative databases: a proposal for standard definitions and preferred measures. Ann Pharmacother 2006, 40(78):1280-1288.

44. Ax F, Ekedahl A: Electronically transmitted prescriptions not picked up at pharmacies in Sweden. Res Social Adm Pharm 6(1):70-77.

45. Reid D, Abramson M, Raven J, Walters HE: Management and treatment perceptions among young adults with asthma in Melbourne: the Australian experience from the European Community Respiratory Health Survey. Respirology 2000, 5(3):281-287.

46. Storm A, Andersen SE, Benfeldt E, Serup J: One in 3 prescriptions are never redeemed: primary nonadherence in an outpatient clinic. J Am Acad Dermatol 2008, 59(1):27-33.

47. Andrade SE, Kahler KH, Frech F, Chan KA: Methods for evaluation of medication adherence and persistence using automated databases. Pharmacoepidemiol Drug Saf 2006, 15(8):565-574, discussion 575-567.

48. DiMatteo MR: Variations in patients' adherence to medical recommendations: a quantitative review of 50 years of research. Med Care 2004, 42(3):200-209.

49. Cramer JA, Benedict A, Muszbek N, Keskinaslan A, Khan ZM: The significance of compliance and persistence in the treatment of diabetes, hypertension and dyslipidaemia: a review. Int J Clin Pract 2008, 62(1):76-87.

50. Kothawala P, Badamgarav E, Ryu S, Miller RM, Halbert RJ: Systematic review and meta-analysis of real-world adherence to drug therapy for osteoporosis. Mayo Clin Proc 2007, 82(12):1493-1501.

51. Ruddy K, Mayer E, Partridge A: Patient adherence and persistence with oral anticancer treatment. CA Cancer J Clin 2009, 59(1):56-66.

52. Chesney MA: Factors affecting adherence to antiretroviral therapy. Clin Infect Dis 2000, 30(Suppl 2):S171-176.

53. Cramer JA, Rosenheck R: Compliance with medication regimens for mental and physical disorders. Psychiatr Serv 1998, 49(2):196-201.

54. Steiner JF, Prochazka AV: The assessment of refill compliance using pharmacy records: methods, validity, and applications. J Clin Epidemio/ 1997, 50(1):105-116.

55. Raebel MA, Carroll NM, Ellis JL, Schroeder EB, Bayliss EA: Importance of including early nonadherence in estimations of medication adherence. Ann Pharmacother 45(9):1053-1060.

56. Cooke CE, Xing S, Lee HY, Belletti DA: You wrote the prescription, but will it get filled? J Fam Pract 60(6):321-327.

57. Xing S, Dipaula BA, Lee HY, Cooke CE: Failure to fill electronically prescribed antidepressant medications: a retrospective study. Prim Care Companion CNS Disord 13(1)

58. Rational use of medicines: progress in implementing the WHO medicine strategy. Report by the secretariat. Executive Board 118th Session World Health Organization; 2006.

59. Jacobsson L, Lindgren B: [What are the costs of diseases?] Swedish. Stockholm Sweden: The National Board of Health and Welfare; 1996.

60. [Statistics - Health and Medical Care] Swedish. Official Statistics of Sweden Stockholm: Socialstyrelsen; 2007. 
61. Ekedahl A, Oskarsson V, Sundberg B, Gustafsson V, Lundberg T, Gullberg B: Impact of postal and telephone reminders on pick-up rates of unclaimed e-prescriptions. Pharm World Sci 2008, 30(5):503-508.

62. Hamilton WR, Hopkins UK: Survey on unclaimed prescriptions in a community pharmacy. J Am Pharm Assoc (Wash) 1997, NS37(3):341-345.

63. Secnik K, Pathak DS, Cohen JM: Postcard and telephone reminders for unclaimed prescriptions: a comparative evaluation using survival analysis. J Am Pharm Assoc (Wash) 2000, 40(2):243-251, quiz 330-241.

64. Schectman JM, Schorling JB, Nadkarni MM, Voss JD: Can prescription refil feedback to physicians improve patient adherence? Am J Med Sci 2004, 327(1):19-24

65. Cutler DM, Everett W: Thinking outside the pillbox-medication adherence as a priority for health care reform. N Engl J Med 362(17):1553-1555.

\section{Pre-publication history}

The pre-publication history for this paper can be accessed here: http://www.biomedcentral.com/1472-6963/11/326/prepub

\section{doi:10.1186/1472-6963-11-326}

Cite this article as: Hovstadius and Petersson: Non-adherence to drug therapy and drug acquisition costs in a national population - a patientbased register study. BMC Health Services Research 2011 11:326.

\section{Submit your next manuscript to BioMed Central and take full advantage of:}

- Convenient online submission

- Thorough peer review

- No space constraints or color figure charges

- Immediate publication on acceptance

- Inclusion in PubMed, CAS, Scopus and Google Scholar

- Research which is freely available for redistribution

Submit your manuscript at www.biomedcentral.com/submit 